\title{
Peningkatan Kemampuan Masyarakat dalam Pola Asuh Aman dan Pertolongan Pertama Kasus Kegawatdaruratan pada Anak
}

\author{
Improving Community Ability in Safe Parenting and First Aid in \\ Emergency Cases for Children \\ Nurlaila $^{1}$, Wuri Utami ${ }^{2}$, Barkah Waladani ${ }^{3}$, Ernawati ${ }^{4}$, Annisa Nurbaiti ${ }^{5}$, \\ Athala Prines Pratunda Wigusti ${ }^{6}$, Farhani Rahmah ${ }^{7}$, Eka Sugiarti ${ }^{8}$ \\ 1,2,3,4,5,6,7,8 Universitas Muhammadiyah Gombong \\ *Corresponding author: nurlaila@unimugo.ac.id
}

Kata Kunci:
Anak;
Kegawatdaruratan
; Pola Asuh

Keywords:

Children;

Emergency;

Parenting

\section{ABSTRAK}

Sebagian besar kasus cedera terjadi dirumah disebabkan oleh kecelakaan lalu lintas, luka bakar, tenggelam, jatuh dan keracunan yang dapat menimbulkan kegawatdaruratan. Cedera pada anak dapat mengakibatkan cedera kepala yang mengakibatkan dampak serius pada perkembangan anak. Kader dan ibu perlu dibekali pola asuh yang aman agar anak terhindar dari cedera serta pertolongan pertama apabila anak mengalami cedera. Tujuan kegiatan ini adalah meningkatkan pengetahuan dan keterampilan kader dan ibu dalam pertolongan pertama kasus kegawatdaruratan pada anak. Pelatihan dilakukan untuk kader (19 orang) dan ibu (23 orang ) yang memiliki anak usia balita di desa bejiruyung, sempor. Media yang digunakan adalah Power point, video pertolongan pertama kasus kegawatdaruratan pada anak, serta alat peraga. Kegiatan diakhiri dengan lomba menyediakan lingkungan yang aman bagi anak. Evaluasi dilakukan melalui kuesioner pre test dan post test serta lembar observasi lingkungan rumah.Hasil menunjukan bahwa terdapat peningkatan pengetahuan dan keterampilan kader dari rerata nilai 35,65 (kurang) menjadi rerata nilai 70,0 (baik) serta peningkatan pengetahuan dan keterampilan ibu dari rerata nilai 51,73 (kurang) menjadi rerata nilai 74,13 (baik). Hasil observasi menunjukan bahwa semua ibu mampu menciptakan rumah yang aman untuk anak. Pelatihan menggunakan metode ceramah dan demonstrasi dengan video dapat meningkatkan pengetahuan dan keterampilan kader serta ibu dalam pertolongan pertama kasus kegawatdaruratan pada anak.

\section{ABSTRACT}

Most cases of injuries occur at home caused by traffic accidents, burns, drowning, falls and poisoning that can cause emergencies. Injuries to children can result in head injuries that have serious implications for a child's development. Cadres and mothers need to be provided with safe parenting patterns so that children avoid injury and first aid if the child is injured.

The purpose of this activity is to increase the knowledge and skills of cadres and mothers in emergency first aid cases in children. The training was conducted for cadres (19 people) and mothers (23 people) who have children under five in the village of Bejiruyung, Sempor. The media used PowerPoint, first aid videos for emergency cases in children, and teaching aids. The activity ended with a competition to provide a safe environment for children. Evaluation was carried out through pre and posttest questionnaires and home environment observation sheets. The results showed that there was an increase in knowledge and skills of cadres from 
less (35.65) to good (70.0) and an increase in knowledge and skills of mothers from less (51.73) to good (74.13). Observation results show that all mothers are able to create safe homes for children. Training using lecture methods and video demonstrations can improve the knowledge and skills of cadres and mothers in first aid for emergency cases in children.

\section{PENDAHULUAN}

Cedera pada anak merupakan masalah kesehatan masyarakat utama yang membutuhkan perhatian segera. Cedera merupakan masalah kesehatan di setiap negara di dunia, menyebabkan lebih dari 5,8 juta kematian per tahun atau 15.000 kematian per hari. Cedera berkontribusi pada kasus kesakitan dan kematian pada anak, Sebagian besar kasus cedera disebabkan oleh kecelakaan lalu lintas, luka bakar, tenggelam dan jatuh. Keracunan juga merupakan cedera paling umum ke-3 pada anak yang dirawat di ruang gawat darurat untuk anak-anak $<16$ tahun Cedera dan keracunan rumah tangga yang umum menyebabkan morbiditas dan mortalitas masa kanak-kanak sebenarnya dapat dicegah (Parmeswaran et al., 2017).

Prevalensi cedera anak adalah $7,1 \%$. Prevalensi cedera masa kanakkanak lebih banyak terjadi pada anak laki-laki, balita dan keluarga inti. Jatuh adalah bentuk cedera yang paling umum dan rumah adalah tempat cedera yang paling umum. Penyebab cedera yang lainnya adalah gigitan anjing dan kecelakaan lalu lintas (Parmeswaran $e t$ al., 2017).

Kasus cedera dan keracunan cukup tinggi terjadi pada anak usia $<5$ tahun. Cedera lebih sering terjadi pada laki-laki lebih dibandingkan perempuan dalam semua jenis cedera yang tidak disengaja. Jatuh adalah kecelakaan yang paling umum terjadi pada anak yang lebih tua dan cedera kepala merupakan konsekuensi utama dari jatuh. Mayoritas anak sembuh total. Menelan hidrokarbon (minyak tanah) adalah keracunan yang paling umum (Kolkur et al., 2020).

Faktor yang mempengaruhi kejadian cedera pada anak adalah usia, jenis kelamin serta tugas perkembangan anak. Faktor resiko cedera kepala dan sindrom post trauma adalah pada anak usia kurang dari 24 bulan. Berbagai masalah dapat muncul pada anak yang mengalami cedera kepala antara lain Cedera Kepala Sedang hingga Berat, Hematoma Subdural Akut, dan hygroma subdural, Post Traumatic Seizure. Tingkat keparahan cedera serta hematoma intraserebral merupakan faktor risiko untuk prognosis yang buruk (Yoon et al., 2017).

Cedera sering dianggap sebagai kejadian yang umum terjadi, namun bisa dicegah. Peran orang tua dan pengasuh sangat besar dalam pencegehan cedera pada anak. Pemahaman orang tua dan pengasuh serta penyediaan lingkungan yang aman dapat mencegah kejadian cedera pada anak. Cedera masa kanak-kanak menyebabkan hilangnya kehadiran sekolah dan beban keuangan keluarga. Situasi ini membutuhkan langkahlangkah kebijakan untuk mendidik masyarakat dan melakukan upaya untuk menyediakan lingkungan yang aman bagi anak-anak (Parmeswaran et al., 2017).

Lingkungan yang sering menyebabkan cedera pada anak adalah adanya jak listrik yang terjangkau anak, kabel listrik yang terbuka, kompor terjangkau anak, peralatan elektronika, bahan kimia untuk 
kebersihan, peralatan rumah tangga seperti pisau dan gunting, serta furniture rumah (Kurniajati et al., 2017). Situasi di Indonesia bahwa belum semua orang tua mampu menciptakan lingkungan yang aman serta memahami tugas perkembangan anak sesuai dengan usia. Pada penelitian menunjukan bahwa sebagian besar upaya orang tua cukup yaitu sebesar 55,8\% dalam pencegahan cedera pada anak di rumah. Masih terdapat pencegahan cedera yang kurang yaitu menyikat lantai kamar mandi agar tidak licin, menghindari penggunaan taplak meja, tidak meninggalkan anak di kamar mandi sendirian dan menjauhkan perabot yang bersudut runcing (Anam et al., 2017).

Desa Bejiruyung merupakan salah satu desa di Kecamatan Sempor yang sebagian masyarakatnya berpendidikan SD yaitu sebesar $29,6 \%$ serta masih banyak masyarakatnya tidak sekolah yaitu sebesar 17,5\%. Latar belakang pendidikan ini dapat mempengaruhi pengetahuan dan perilaku masyarakat dalam pola asuh anak dirumah. Hasil wawancara dengan bidan desa juga menunjukan bahwa belum ada kegiatan penyuluhan tentang pola asuh yang aman bagi anak serta tata laksana kegawatdaruratan pada anak di Desa Bejiruyung baik pada kader maupun pada masyarakat seacara umum. Kasus cedera pada anak yang paling sering terjadi di Desa Bejiruyung adalah luka akibat jatuh yaitu sekitar 50\% anak balita pernah mengalaminya. Kasus cedera kecelakaan lalu lintas dan tenggelam tidak terjadi pada sekitar 3 tahun terakhir. Situasi ini perlu terus dipertahankan dan ditingkatkan melalui kegiatan pelatihan ini
Tujuan kegiatan ini adalah meningkatkan pengetahuan dan keterampilan masyarakat dalam pencegahan cedera pada anak dirumah serta meningkatkan keterampilan masyarakat dalam pertolongan pertama kasus kegawatdaruratan pada anak.

\section{METODE}

Metode yang digunakan dalam kegiatan ini meliputi discovery learning yaitu mencari referensi mengenai perkembangan anak, pola asuh yang aman dan prosedur pertolongan pertama pada kasus kegawatdaruratan pada anak dirumah, lecture, simulasi dan lomba. Media yang digunakan adalah power point template, video pertolongan pertama kasus kegawatdaruratan pada anak, dan alat peraga. Materi yang disampaikan saat pelatihan adalah tugas perkembangan dan risiko cedera pada anak, pola asuh yang aman untuk anak, serta pertolongan pertama kasus kegawatdaruratan pada anak.

Sasaran kegiatan ini adalah kader balita dan ibu yang memiliki balita di Desa Bejiruyung Kecamatan Sempor Kabupaten Kebumen. Pelatihan kader dan ibu balita dilakukan selama masing-masing 1 hari. Pre test dilakukan sebelum pelatihan dengan membagikan kuesioner pengetahuan dan keterampilan. Post test dilakukan setelah pelatihan dengan membagikan kuesioner yang sama. Penilaian terhadap rumah peserta pelatihan dilakukan 1 minggu setelah pelatihan dengan menggunakan lembar observasi. Kegiatan pelatihan dan observasi ditunjukan pada gambar berikut ini: 


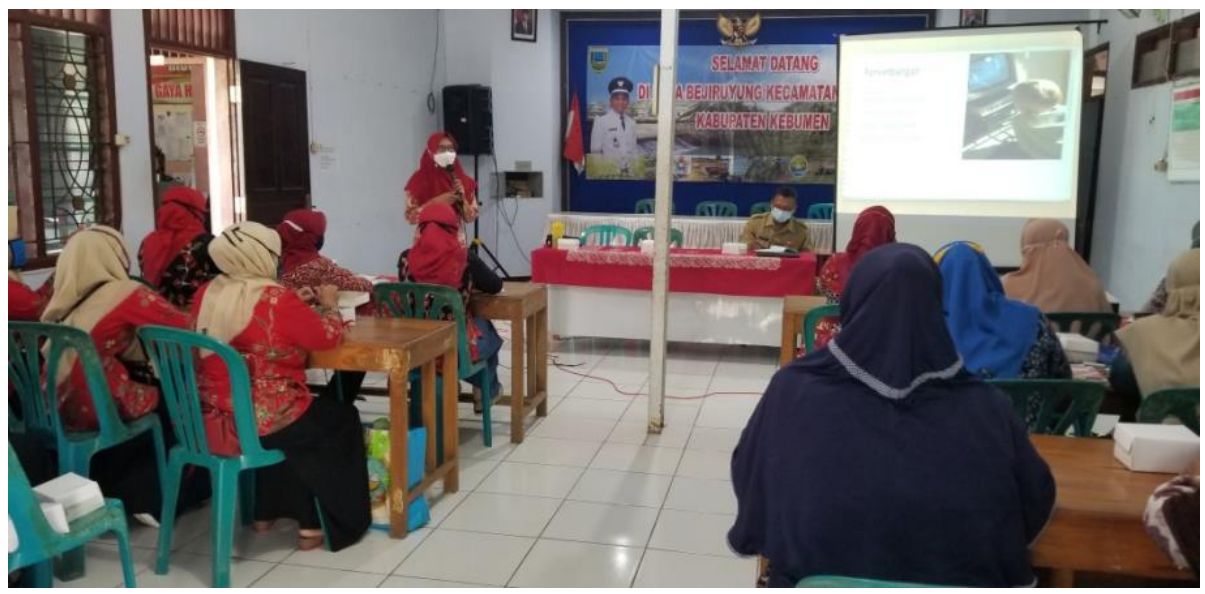

Gambar 1. Pelatihan kader balita

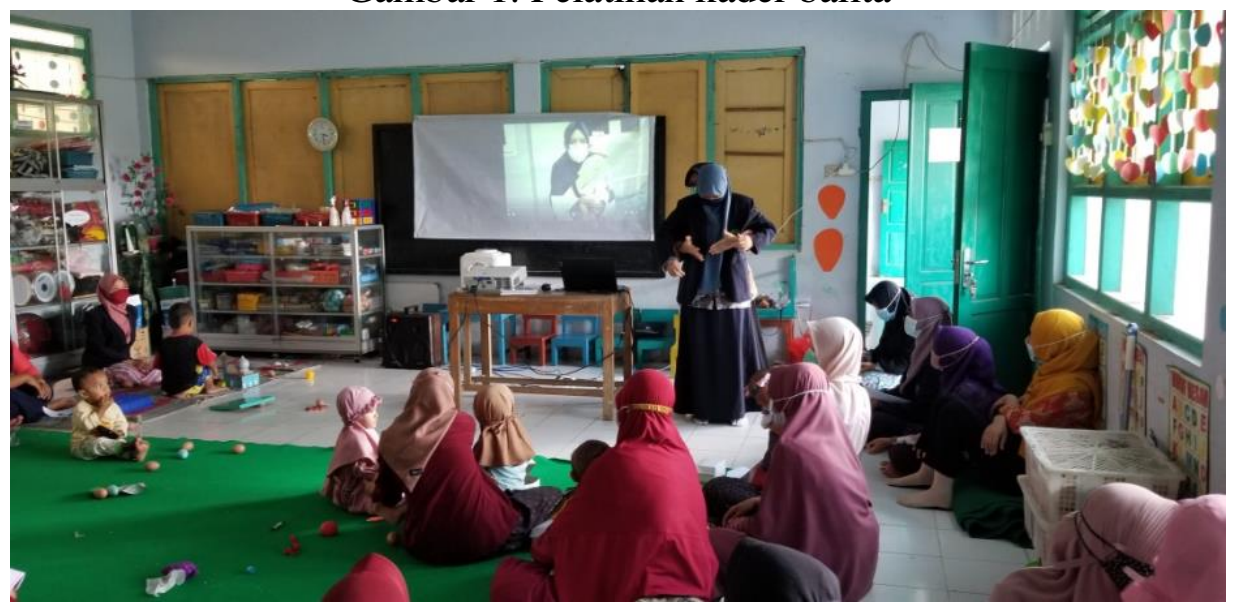

Gambar 2. Pelatihan ibu balita

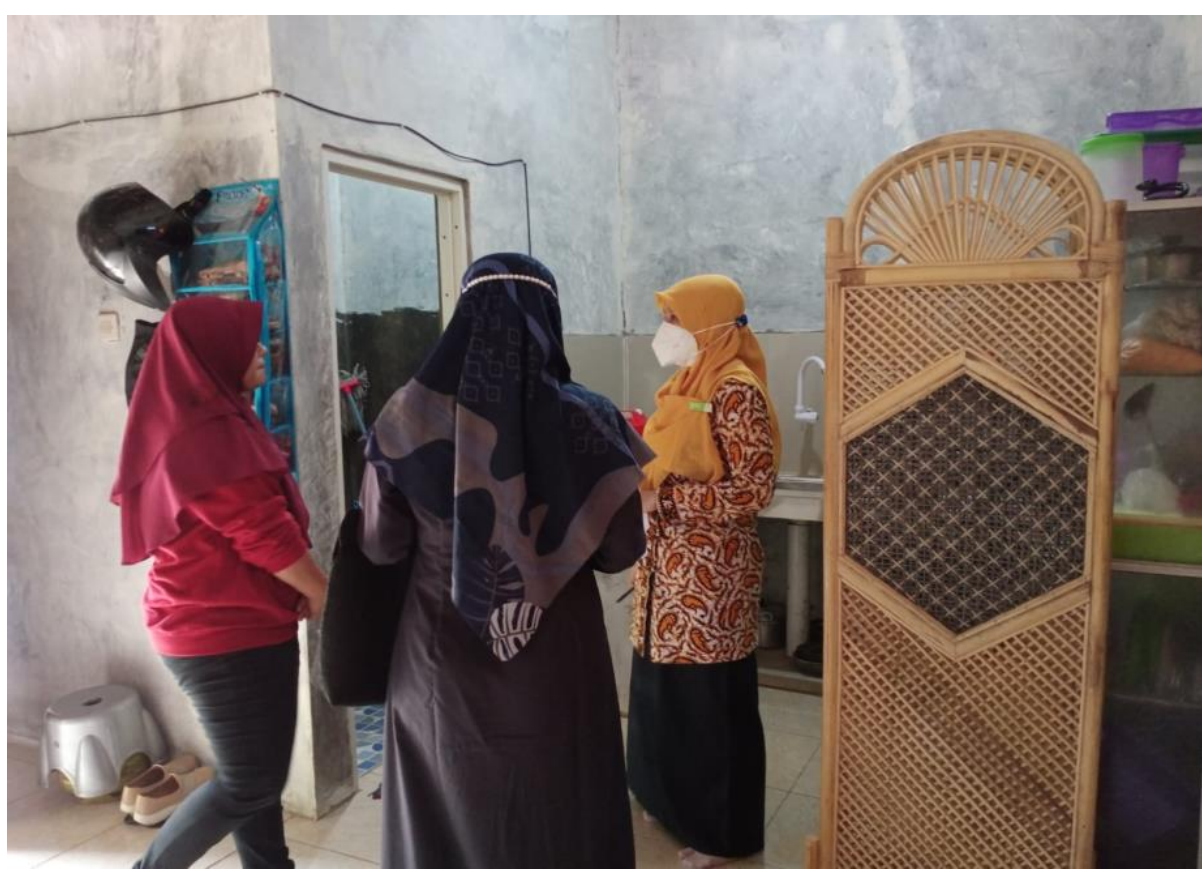

Gambar 3. Observasi penilaian rumah peserta pelatihan 
HASIL DAN PEMBAHASAN

\section{Pengetahuan dan Keterampilan Kader}

Pelatihan

pertolongan

pertama kasus kegawatdaruratan pada anak di desa Bejiruyung telah dilaksanakan selama bulan Maret
2021. Peserta pelatihan adalah kader kesehatan dan ibu yang memiliki balita di desa bejiruyung. Hasil penilaian pre dan post test kader balita adalah disajikan pada tabel 1 .

Tabel 1. Hasil penilaian pre test dan pos test kader kesehatan

\begin{tabular}{|c|c|c|}
\hline No & $\begin{array}{c}\text { Rerata nilai pre test } \\
\text { kader kesehatan }\end{array}$ & $\begin{array}{c}\text { Rerata nilai pos test kader } \\
\text { kesehatan }\end{array}$ \\
\hline 1 & 35,65 & 70,00 \\
\hline 2 & Kurang & Baik \\
\hline
\end{tabular}

Sumber: Data Primer Hasil Penilaian

Berdasarkan tabel diatas menunjukan bahwa terdapat peningkatan pengetahuan dan keterampilan kader setelah pelatihan. Metode yang digunakan dalam pelatihan ini adalah ceramah, tanya jawab dan media audio visual berupa video pertolongan pertama pada kasus kegawatdaruratan pada anak. Hal ini sesuai dengan penelitian Akhmadi et al. (2021) yang menunjukan bahwa metode penyampaian pembelajaran dengan demonstrasi dan role play secara signifikan meningkatkan sikap kader sebagai pendidik kesehatan $92 \mathrm{i}$ ibu atau orang tua di n..uvyarakat. Media audio visual dapat menunjukan secara jelas pada kader mengenai pertolongan ketika anak mengalami cedera. Media audio visual dapat diulang kapan saja oleh kader bahkan setelah selesai pelatihan. Materi yang diulang-ulang dapat memberikan pemahaman yang lebih mendalam pada kader. Kader perlu memiliki pengetahuan dan keterampilan yang baik agar dapat mengajarkannya kepada masyarakat sebagai bentuk keberlanjutan program pengabdian kepada masyarakat.

Penyuluhan dengan media audio visual mempengaruhi pengetahuan ibu hamil dalam pencegahan stunting (Arsyati, 2019). Video pembelajaran memiliki dua jenis media yaitu audio (mendengar) dan visual (melihat) yang berarti dapat membantu kader mempelajari tulisan, gambar dan suara mengenai pertolongan pertama kasus cedera pada anak. Adanya video ini juga dapat digunakan oleh kader untuk mengedukasi masyarakat mengenai keterampilan pertolongan pertama kasus cedera pada anak. Pelatihan kader dengan metode yang tepat mengenai pola asuh dapat membekali kader untuk dapat memberikan edukasi kepada masyarakat terutama ibu.

\section{Pengetahuan Pelatihan Ibu}

Hasil pelatihan pre dan post test ibu disajikan pada tabel 2.

Tabel 2. Hasil penilaian pre test dan pos test ibu

\begin{tabular}{|c|c|c|}
\hline No & $\begin{array}{c}\text { Rerata nilai pre test } \\
\text { kader ibu balita }\end{array}$ & $\begin{array}{c}\text { Rerata nilai pos test kader ibu } \\
\text { balita }\end{array}$ \\
\hline 1 & 51,73 & 74,13 \\
\hline 2 & Kurang & Baik \\
\hline
\end{tabular}




\section{Sumber: Data Primer Hasil Penilaian}

Berdasarkan tabel 2 menunjukan bahwa terdapat peningkatan pengetahuan dan keterampilan ibu setelah pelatihan.

Pada pre test pengetahuan dan keterampilan ibu dalam kategori kurang dan pada post test pelatihan pengetahuan dan keterampilan menjadi baik. Pendidikan kesehatan dapat meningkatkan pengetahuan dan keterampilan ibu dalam pencegahan cedera pada anak. Hal ini sesuai dengan penelitian Sari \& Saputro (2015) yang menunjukan bahwa ada pengaruh edukasi kepada keluarga tentang tersedak terhadap pengetahuan dan keterampilan keluarga. Sebagian besar pengetahuan kurang sebelum dilakukan edukasi, dan tidak terampil, setelah edukasi pengetahuan menjadi baik dan terampil. Masyarakat belum banyak mendapatkan informasi mengenai pola asuh yang aman dan cara pencegahan serta pertolongan cedera pada anak sebelum adanya pelatihan ini. Ibu sebagai pengasuh utama anak sebaiknya memiliki keterampilan yang baik untuk memberikan pertolongan pertama pada anak ketika terjadi cedera.

Pola asuh yang aman juga diperlukan oleh orang tua untuk memberikan lingkungan yang aman dan nyaman mendukung pertumbuhan dan perkembangan anak. Pola asuh orang tua berhubungan dengan kejadian cedera pada anak. Pola asuh yang banyak diterapkan oleh orang tua adalah demokratis. Sebagian besar orang tua yang menerapkan pola asuh demokratis, anak tidak mengalami cedera. Pola asuh orang tua akan memberikan gambaran nyata pada anak bagaimana dia harus bersikap dan berperilaku (Ristia et al., 2020). Pengetahuan menjadi dasar penting bagi orang tua untuk bersikap dan berperilaku terutama dalam pengasuhan anak dirumah. Ibu merupakan orang tua yang memiliki peran besar dalam pengasuhan anak. Pengetahuan orang tua yang baik mengenai pola asuh yang aman untuk anak dapat mempengaruhi pola asuhnya dirumah. Pengetahuan bisa didapatkan sendiri orang seseorang melalui orang lain atau media sosial, bisa juga didapatkan melalui kegiatan pelatihan (M. Sari \& Rahmi, 2017).

\section{Keterampilan Ibu}

Penilaian keterampilan ibu dilakukan melalui observasi pada lingkungan rumah ibu yang telah mengikuti pelatihan. Hasil observasi menunjukan 5 ibu dengan kondisi rumah yang aman untuk pengasuhan disajikan pada tabel 3 .

Tabel 3. Hasil penialian 5 terbaik rumah masyarakat desa Bejiruyung

\begin{tabular}{|c|c|c|c|}
\hline No & $\begin{array}{c}\text { Inisial } \\
\text { Responden }\end{array}$ & Nilai & Kategori \\
\hline 1 & Ny. A & 99,07 & Sangat Baik \\
\hline 2 & Ny.O & 87,9 & Sangat Baik \\
\hline 3 & Ny. D & 84,25 & Sangat Baik \\
\hline 4 & Ny. T & 82,4 & Sangat Baik \\
\hline 5 & Ny. M & 80,5 & Sangat Baik \\
\hline
\end{tabular}

Sumber: Data Primer Hasil Observasi 


\section{JURNAL EMPATI}

Edukasi Masyarakat, Pengabdian dan Bakti

Vol. 2, No. 1 April 2021 Hal 88 - 95

ISSN 2774-4442 (print) dan ISSN 2774-2296 (online)

Berdasarkan tabel diatas menunjukan bahwa ibu telah mengaplikasikan pengetahuan mengenai pola asuh yang aman dan cara menyediakan lingkungan yang aman untuk anak. Rumah yang aman merupakan salah satu cara mencegah terjadinya cedera pada anak. Pengetahuan yang baik dapat mempengaruhi perilaku ibu dalam pencegahan cedera pada anak. Pola asuh orang tua mempengaruhi perilaku anak dalam hidup sehat (Chrisnawati \& Suryani, 2020). Rumah yang sehat dan aman dapat mendukung pertumbuhan dan perkembangan anak. Anak yang aman bermain dirumah akan mencegah terjadinya cedera yang bisa menyebabkan hospitalisasi pada anak. Anak yang sehat akan mencapai setiap tahap tugas perkembangannya dengan baik

\section{SIMPULAN}

Kesimpulan pada kegiatan ini adalah pelatihan melalui metode ceramah dan simulasi menggunakan video dapat meningkatkan 94 rengetahuan dan keterampilan .ader dan ibu dalam pencegahan cedera pada anak dirumah. Pelatihan ini juga meningkatkan keterampilan kader dan ibu balita dalam pertolongan pertama kasus kegawatdaruratan pada anak di rumah. Kader kesehatan sebaiknya memberikan informasi mengenai tindakan pencegahan cedera pada anak kepada seluruh masyarakat. Puskesmas sebaiknya melakukan pelatihan kepada masyarakat secara rutin untuk meningkatkan perilaku hidup sehat.

\section{DAFTAR PUSTAKA}

Akhmadi, Sunartini, Haryanti, F., Madyaningrum, E., \& Sitaresmi, M. N. (2021). Effect of Care for Child Development Training on Cadres' Knowledge, Attitude, and Efficacy in Yogyakarta, Indonesia. Belitung Nursing Journal, 18.

Anam, A. K., Mulyadi, A., \& Sagar, D. W. (2017). Upaya Orang Tua dalam Pencegahan Cedera Anak Balita di Rumah. Jurnal Ners Dan Kebidanan, 4(1), 012-016. https://doi.org/10.26699/jnk.v4i1. art.p012-016

Arsyati, A. M. (2019). Pengaruh Penyuluhan Media Audiovisual Dalam Pengetahuan Pencegahan Stunting Pada Ibu Hamil Di Desa Cibatok 2 Cibungbulang. Promotor: Jurnal Mahasiswa Kesehatan Masyarakat, 2(3), 182. https://doi.org/10.32832/pro.v2i3 .1935

Chrisnawati, Y., \& Suryani, D. (2020). Hubungan Sikap, Pola Asuh Keluarga, Peran Orang Tua, Peran Guru dan Ketersediaan Sarana Dengan Perilaku Hidup Bersih dan Sehat. Jurnal Ilmiah Kesehatan Sandi Husada, 12(2), 1101-1110.

https://doi.org/10.35816/jiskh.v1 $2 \mathrm{i} 2.484$

Kolkur, K. S., Chavan, S., \& Agarkhedkar, S. (2020). Study of Common Household Injuries and Poisoning in Children in Tertiary Care Hospital of Western Maharashtra. International Journal Dental and Medical Sciencer Research, 3(1), 70-76. https://doi.org/10.35629/525203017076 
Kurniajati, S., Astarani, K., \& Sari, D. I. (2017). Risiko Cidera oleh Faktor Lingkungan Berdasarkan Anticipatory Guidance pada Anak di Tempat Penitipan Anak. Jurnal STIKES, 10(2), 105-112.

Parmeswaran, G. G., Kalaivani, M., Gupta, S. K., Goswami, A. K., \& Nongkynrih, B. (2017). Unintentional Childhood Injuries in Urban Delhi: A CommunityBased Study. Indian Journal of Community Medicine: Official Publication of Indian Association of Preventive \& Social Medicine, 42(1), $8-12$. https://doi.org/10.4103/09700218.199791

Ristia, A., Utari, R., \& Faridah, H. (2020). Hubungan Pola Asuh Orang Tua Dengan Kejadian Cedera Pada Anak Usia 3-6 Tahun di PAUD dan TK Kemala Bhayangkari 06 Kota Langsa. JP2K Jurnal Pendidikan Dan Praktik Kesehatan, 3(2), 117126.

Sari, A. S., \& Saputro, Y. A. (2015). Pengaruh Edukasi Keluarga tentang Pencegahan Perawatan Cedera Tersedak pada Anak terhadap Pengetahuan dan Keterampilan Keluarga. $E$ JOurnal STKIP PGRI Pacitan, 5(December), 118-138.

Sari, M., \& Rahmi, N. (2017). FaktorFaktor yang Mempengaruhi Pola Asuh Orang Tua pada Anak Balita di Desa Batoh Kecamatan Lueng Bata Kota Banda Aceh. Journal of Healthcare Technology and Medicine, 3(1), 94. https://doi.org/10.33143/jhtm.v3i 1.262

Yoon, S.-Y., Choi, Y.-J., Park, S.-H., Hwang, J.-H., \& Hwang, S. K. (2017). Traumatic Brain Injury in
Children under Age 24 Months: Analysis of Demographic Data, Risk Factors, and Outcomes of Post-traumatic Seizure. Journal of Korean Neurosurgical Society, 60(5), 584-590. https://doi.org/10.3340/jkns.2016 .0707 .008 